\title{
Correlates of Satisfaction with Community Reintegration Among Stroke Survivors in Kano Metropolis
}

\author{
Badaru U.M., ${ }^{1}$ Nasir A., ${ }^{1}$ Mohammed J., ${ }^{1}$ Abba M.A., ${ }^{1}$ Ogwumike 0.O., ${ }^{2}$ Adeniyi A.F. ${ }^{2}$ \\ ${ }^{1}$ Department of Physiotherapy, Faculty of Allied Health Sciences, Bayero University, Kano, Nigeria \\ ${ }^{2}$ Department of Physiotherapy, College of Medicine, University of Ibadan, Ibadan, Nigeria \\ Correspondence: Umaru Muhammad Badaru, Department of Physiotherapy, Faculty of Allied Health Sciences, \\ Bayero University Kano, Nigeria・Email: badaruum@yahoo.com
}

\section{SUMMARY}

The aim of stroke rehabilitation is to ensure successful reintegration of stroke survivors (SSV) into their communities to enable them effectively discharge their physical, economic and social roles. This study assessed factors related to satisfaction with community reintegration (CR) of SSV in Kano metropolis.

It was a cross sectional survey that recruited 68 consenting SSV using the purposive sampling technique. Assessments of CR, physical function, social support and depression were done with Reintegration to Normal Living Index (RNLI), Functional Independence Measure (FIM), Multidimensional Scale of Perceived Social Support (MPSS) and Patient Health Questionnaire (PHQ-9) respectively. Spearman Rank Order Correlation and Wilcoxon Sign Rank tests were used to analyze the data at a level of statistical significance of $0.05 \mathrm{using}$ SPSS version 16.0.

A total of 36(52.9\%) males and 32(47.1\%) females with mean age of $59.69 \pm 13.568$ years took part in the study. About $50(73.6 \%)$ are modified dependent and $46(67.6 \%)$ enjoyed moderate social support. The majority $87 \%(\mathrm{~N}=59)$ experienced severe restrictions to $\mathrm{CR}$. There were significant correlations between RNLI and each of MSPSS (rho=0.249, $\mathrm{p}=0.041)$ and FIM (rho $=0.406, \mathrm{p}=0.001)$ scores. Occupational status $(\mathrm{Z}=-6.693$, $p=0.000)$, income $(Z=-3.910, p=0.000)$ and driving status $(Z=-5.292, p=0.000)$ changed significantly.

It was concluded that the level of CR of most SSV in Kano metropolis was not satisfactory with significant loss of employment and earnings and ability to drive post stroke. Increased levels of social support and adequate recovery of physical functions are likely to improve satisfaction with CR.

KEY WORDS: stroke, satisfaction, community reintegration, social support, driving, return to work

\section{INTRODUCTION}

Stroke is one of the major causes of long-term disability that could negatively affect survivors' physical (Obembe et al, 2013; Hamzat et al, 2014) and emotional health (Obembe et al, 2013). Most stroke survivors have enormous challenges in participating in both domestic and community-related activities post-discharge (Salter et al, 2013). Community reintegration involves the ability of the stroke survivor to "resume age, gender or culture appropriate roles or statuses including independence or interdependence in decision making and productive behaviors carried out as a part of multi-varied relationships with family, friends and others in natural community settings" (Dijkers, 1998). Previous studies have shown that impairment in physical (Beckley, 2007; Baseman et al 2010; Akosile et al, 2012; Obembe et al, 2013; Hamzat et al, 2014), social (Beckley, 2007) and psychological functioning (Pang et al, 2007; Chau et al, 2009; Baseman et al 2010, Obembe et al, 2013) in stroke survivors could have negative influence on their satisfaction with community reintegration.

Studies conducted in the Southern region of Nigeria have reported that longer post-stroke duration (Obembe et al, 2010), higher levels of motor recovery (Obembe et al, 2013; Hamzat et al, 2014) and lower levels of depression in stroke survivors (Obembe et al, 2013) were all related to 
improved levels of satisfaction with community reintegration. There is however a dearth of studies on community reintegration among stroke survivors who live in the northern part of Nigeria. This study therefore assessed the factors that are related to satisfaction with community reintegration of stroke survivors in Kano metropolis.

\section{METHODOLOGY}

The cross-sectional survey design was used to recruit all consenting stroke survivors using purposive sampling. Patients with repeat stroke, stroke duration $<3$ months and hemiparesis due to head injury were excluded. The study was conducted in the Physiotherapy departments of Aminu Kano Teaching Hospital, Murtala Mohammed Specialist Hospital and Sir Sanusi Specialist Hospitals, Kano.

\section{Data collection procedure}

Ethical approval was sought and obtained from the managements of Aminu Kano Teaching Hospital (AKTH) and the Kano State Hospitals Management Board before commencement of data collection. The research procedure was explained to each of the participants after which they were asked to sign the informed consent form. The consent in this study included voluntariness of participation, anonymity and confidentiality of the information provided. All the research instruments were administered to the study participants by the researchers.

\section{Assessment of functional status of stroke survivors}

The functional independence measure (FIM) was used to assess the functional status of the participants. It has internal consistencies of $\alpha=0.94$ (Brosseau and Wolfson, 1994) and $\alpha \geq 0.84$ (Hsueh et al, 2002), inter-rater reliability ICC $=0.83$ (Brosseau and Wolfson, 1994) and ICC $\geq 0.83$ (Hsueh et al, 2002); and concurrent validity Rho $\geq 0.92$ (Hsueh et al, 2002).

The FIM is a performance-based measure in which participants are rated based on their ability to carry out specific motor tasks. It consists of 18 items that assess motor (13 items) and cognitive (5 items) functions (Sprint et al, 2015). The motor subscale consists of self-care activities such as eating, grooming, bathing, dressing of upper and lower body and toileting. The sphincter control items include bladder and bowel management. The items on transfer include bed/chair, tub/shower and toilet transfers. The locomotion items were walk/wheelchair and stair mobility. The cognitive subscale included items on communication such as comprehension and expression; and social cognition that included social interaction, problem solving and memory. The instrument was directly administered on the patients by asking them to perform FIM tasks. They were asked to give responses on tasks relating to toileting and toilet transfer, bathing, and bladder and bowel management since such items cannot be assessed directly at the outpatient clinic.

\section{Scoring of individual items on the scale}

Each FIM item was rated on a 7-point ordinal scale that ranges from total assistance (a score of 1) to complete independence (a score of 7), with higher scores indicating better function as follows:

$1=$ patient is unable to perform required task (performs less than $25 \%$ of the task or needs 2 people to help)

$2=$ maximal assistance (patient performs only about 25 $49 \%$ of the task)

$3=$ moderate assistance (patient performs $50-74 \%$ of the task)

$4=$ minimal assistance (patient performs $75 \%$ or more of the task)

$5=$ patient required supervision (can perform the task but needs some cues)

$6=$ modified independence (patient uses assistive device or takes more time but is able to perform the task independently)

7 = complete independence (patient perform the task safely and timely) (Linacre, 2000; Konzen, and Shin, 2006)

\section{Calculating Mean FIM Score for Each Participant}

The total score was obtained as the sum of all the task scores on the FIM scale (Sprint et al, 2015). The lowest total FIM score was 18 and the highest was 126 (Meta data online registry, 2012). The mean function score was obtained by adding all individual item scores and dividing the result obtained by 18 . The least possible mean function score was 1 and the highest mean was 7 . Since each of the items on FIM can be scored individually for example, 1-2 completely dependent, 3-5 modified dependence, and 6-7 completely independent (Konzen, and Shin, 2006; Linacre, 2000), the rating of mean function score for a participant was done in the same way by accommodating decimals.
1. $1-2.4$ (fully dependent)
2. $2.5-5.4$ (modified dependence)
3. $5.5-7$ (fully independent) 


\section{Assessment satisfaction with community reintegration}

Community reintegration was measured using Reintegration to Normal Living Index (RNLI). The RNLI is an 11-item questionnaire that is used to measure perceived level of satisfaction with community reintegration (Wood-Dauphinee et al, 1988). It assesses the level of satisfaction with participation in recreational, social, and community-related activities, including satisfaction with family roles (Mayo et al, 2000). The RNLI is a reliable instrument with Cronbach's alpha values ranging from 0.87 (Hitzig et al, 2012) to 0.97 (Mothabeng et al, 2012). It has good construct validity, with all items having loadings greater than 0.71 (Mothabeng et al, 2012).

\section{Scoring of RNLI}

Each of the 11 items of the RNLI was rated on a 4-point ordinal scale, with scores ranging from 1 'does not describe my situation' to 4 'fully describes my situation'. The least possible score was 11 and the highest possible was 44, and these were transformed to scores between $25 \%$ (11) and $100 \%$ (44). Participants' scores were summed up and divided by highest possible score (i.e. 44) and the result obtained was multiplied by 100 . The higher the score the better the level of satisfaction with community reintegration.

\section{Rating of community reintegration}

A score of $100 \%$ was rated full satisfaction, $60 \%-99 \%$ represented mild to moderate restriction and a score less than $60 \%$ was considered to show severe restriction to community reintegration (Pang et al, 2007; Murtezani et al, 2009).

\section{Assessment of Social Support}

Social support was evaluated with the Multidimensional Scale of Perceived Social Support (MSPSS). The MSPSS is a 12-item instrument that evaluates perceived social support using 3 domains, namely family, friends and significant others. It is a valid measure of perceived social support in an African community (Stewart et al, 2014). Internal consistency scores of $\alpha=0.899$ (Rizwan and Aftab, 2009), $\alpha=0.92$ (Akhtar et al, 2010) and $\alpha=0.87$ (Wongpakaran et al, 2011) have been reported. Test-retest reliability reported were ICC $=0.76$ (Rizwan and Aftab, 2009) and ICC $=0.84$ (Wongpakaran et al, 2011). Construct validity was supported by the inverse relationship MSPSS has with psychological distress (Akhtar et al, 2010).

\section{Scoring of MSPSS}

Each of the 12 items on the scale was rated on a 7-point ordinal scale with scores ranging from 1 'very strongly disagree' to 7 'very strongly agree'. The least possible total score on the scale was 12 and the highest was 84 . A total score of 12-48 indicated low, 49-68 showed moderate, and 69-84 showed high level of perceived social support (Hannan et al, 2016).

\section{Assessment of depression}

With the understanding that impairment of psychological functioning may have negative impact on the level of satisfaction with community reintegration post-stoke, the depression status of study participants was assessed with the Patient Health Questionnaire (PHQ-9). The instrument has internal consistencies of $\alpha=0.857$, (Bian et al, 2011) and $\alpha=0.83$ (Hammash et al, 2013), test-retest reliability $\mathrm{r}=0.947$ and sensitivity of $91 \%$ (Bian et al, 2011). It has specificity of $97 \%$ (Bian et al, 2011) and $88 \%$ for both major depression and scores $\geq 10$ (Kroenke et al, 2001). According to Hammash et al (2013), PHQ-9 has a high concurrent validity with Beck depression inventory II Rho $=0.80$.

\section{Scoring of PHQ-9}

PHQ-9 has 9 items and each item was scored on a 4-point Likert scale with scores ranging from 0 point 'not at all' to 3 points 'nearly every day'. The lowest possible score was 0 point and the highest possible was 27 points. A score of 1-4 points was rated as minimal depression, 5-9 points as mild depression, 10-14 points as moderate depression, 15-19 points as moderately severe depression and 20-27 points as severe depression (Kroenke et al 2001).

\section{Data analysis}

The characteristics of stroke survivors were summarized using descriptive statistics of mean, frequency and standard deviation and illustrated using tables and chart. The Wilcoxon sign rank test was used to compare occupational status, driving status and the economic status of the stroke survivors before and after stroke. Spearman rank order correlation was used to assess the relationship between motor function, perceived social support depression and community reintegration. The statistical tests were conducted using SPSS version 16.0 at 0.05 level of significance. 


\section{RESULTS}

Sixty-eight (68) stroke survivors participated in this study; $36(52.9 \%)$ male and $32(47.1 \%)$ female. The mean age of the participants was $59.69 \pm 13.57$ years and the majority, $45(66.2 \%)$, were married (table 1$)$. Prior to the stroke, 8 $(11.8 \%)$ participants were civil servants, 43 (63.2\%) were self-employed, 13 (19.1) were unemployed, and 4 (5.9\%) had retired. It was observed that after the stroke only one participant $(1.5 \%)$ still worked as a civil servant while the majority $58(85.3 \%)$ were unemployed (table 1$)$.

Table 1. Characteristics of participants before and after stroke $(\mathrm{N}=68)$

\begin{tabular}{|c|c|c|}
\hline Variable & Frequency (\%) & \\
\hline Age categories (years) & $\mathrm{n}(\%)$ & \\
\hline $30-50$ & $20(29.4)$ & \\
\hline $51-70$ & $39(57.4)$ & \\
\hline $71-90$ & $9(13.2)$ & \\
\hline \multicolumn{3}{|l|}{ Gender } \\
\hline Male & $36(52.9)$ & \\
\hline Female & $32(47.1)$ & \\
\hline \multicolumn{3}{|l|}{ Marital Status } \\
\hline Married & $45(66.2)$ & \\
\hline Divorced & $19(27.9)$ & \\
\hline Single & $4(5.9)$ & \\
\hline \multicolumn{3}{|l|}{ Hand Dominance } \\
\hline Right & $60(88.2)$ & \\
\hline Left & $8(11.8)$ & \\
\hline \multicolumn{3}{|l|}{ Speech } \\
\hline Fluent & $59(86.8)$ & \\
\hline Dysarthric & $9(13.2)$ & \\
\hline \multicolumn{3}{|l|}{ Hemiplegic Side } \\
\hline Right & $26(38.2)$ & \\
\hline Left & $42(61.8)$ & \\
\hline \multicolumn{3}{|l|}{ Stroke Duration } \\
\hline 3-6month & $34(50)$ & \\
\hline 7-12month & $10(14.7)$ & \\
\hline 13-24month & $1(1.5)$ & \\
\hline 2years & $23(33.8)$ & \\
\hline Occupation & Before Stroke & After Stroke \\
\hline Civil servant & $8(11.8)$ & $1(1.5)$ \\
\hline Self employed & $43(63.2)$ & $4(5.9)$ \\
\hline Unemployed & 13(19.1) & $58(85.3)$ \\
\hline Retired & $4(5.9)$ & $5(7.4)$ \\
\hline \multicolumn{3}{|l|}{ Monthly Income } \\
\hline Below minimum wages & $47(69.1)$ & 63(92.6) \\
\hline Low wages & $8(11.8)$ & $4(5.9)$ \\
\hline Average wages & $13(19.1)$ & $1(1.5)$ \\
\hline \multicolumn{3}{|l|}{ Driving } \\
\hline Yes & $29(42.6)$ & $1(1.5)$ \\
\hline No & $39(57.4)$ & $67(98.5)$ \\
\hline
\end{tabular}

Key: $\mathrm{n}=$ frequency, $\%=$ percent
In addition, 17 (25\%) participants had mild depression while the majority, $46(67.6 \%)$, had moderate level of social support and severe restrictions to their community reintegration $59(86.8 \%)$ as presented in figure 1 . Additionally, correlations were significant between RNLI and each of social support $(\mathrm{rho}=0.249, \mathrm{p}=0.041)$ and physical functions (rho $=0.406, \mathrm{p}=0.001$ ) (table 2). Furthermore, occupation $(Z=-6.693, p=0.000)$, income $(Z=-3.910, p=0.000)$ and driving status $(Z=-5.292$, $\mathrm{p}=0.000$ ) of the study participants were significantly changed after the stroke event (table 3 ).

Table 2. Correlation between RNLI and each of depression, functional status, and patients' socio-demographics $(\mathrm{N}=68)$

\begin{tabular}{lcl}
\hline Variable & Rho & P-value \\
\hline Depression & -0.197 & 0.108 \\
Social support & 0.249 & $0.041^{*}$ \\
Age category & -0.171 & 0.163 \\
Gender & 0.066 & 0.590 \\
Functional status & 0.406 & $0.001^{*}$ \\
Hand dominance & -0.143 & 0.246 \\
Speech & -0.153 & 0.214 \\
Hemiplegic side & -0.229 & 0.061 \\
Stroke duration & 0.132 & 0.283 \\
Before stroke monthly income & 0.024 & 0.843 \\
After stroke monthly income & -0.110 & 0.372 \\
Driving status before stroke & 0.074 & 0.551 \\
Driving status after stroke & 0.048 & 0.699 \\
Marital status & -0.105 & 0.393 \\
\hline Key: Rho spearman's rank orer correlation, &
\end{tabular}

Key: Rho $=$ spearman's rank order correlation, *significant $(\mathrm{P}<0.05)$

Table 3. Comparisons of driving, income and occupational status of study participants pre-stroke and post stroke

\begin{tabular}{|c|c|c|c|c|c|c|c|}
\hline Variable & Time & $\mathrm{N}$ & $\begin{array}{c}\text { Mean } \\
\text { rank }\end{array}$ & $\begin{array}{c}\text { Sum of } \\
\text { ranks }\end{array}$ & Z & $\begin{array}{l}\text { Effect } \\
\text { size }(r)\end{array}$ & P-value \\
\hline \multirow[t]{2}{*}{$\begin{array}{l}\text { Occup. } \\
\text { status }\end{array}$} & $\begin{array}{l}\text { Before } \\
\text { stroke }\end{array}$ & 51 & 25.50 & 1275.00 & -6.693 & 0.663 & $\mathrm{P}=0.000^{*}$ \\
\hline & $\begin{array}{l}\text { After } \\
\text { stroke }\end{array}$ & 5 & 0.00 & 0.00 & & & \\
\hline \multirow[t]{2}{*}{ Income } & $\begin{array}{l}\text { Before } \\
\text { stroke }\end{array}$ & 68 & 11.22 & 6.50 & -3.910 & 0.335 & $\mathrm{P}=0.000^{*}$ \\
\hline & $\begin{array}{l}\text { After } \\
\text { stroke }\end{array}$ & 68 & 6.50 & 224.50 & & & \\
\hline \multirow[t]{2}{*}{$\begin{array}{l}\text { Driving } \\
\text { status }\end{array}$} & $\begin{array}{l}\text { Before } \\
\text { stroke }\end{array}$ & 29 & 14.50 & 406.00 & -5.292 & 0.695 & $\mathrm{P}=0.000^{*}$ \\
\hline & $\begin{array}{l}\text { After } \\
\text { stroke }\end{array}$ & 1 & 0.00 & 0.00 & & & \\
\hline
\end{tabular}




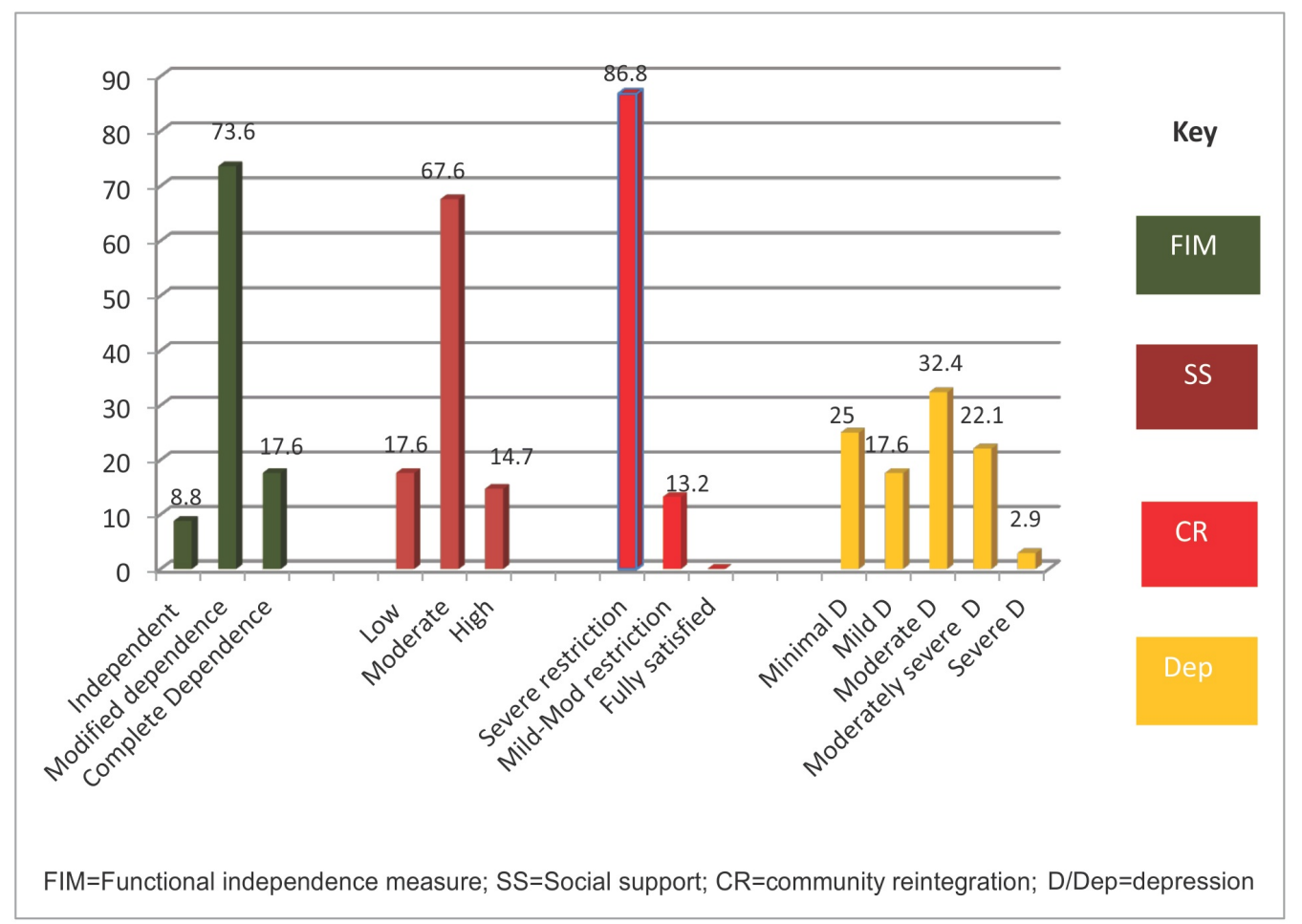

Figure 1. Motor function, social support and reintegration levels of participants.

\section{DISCUSSION}

In this study, more than three-quarters of stroke survivors had severe restrictions to their community reintegration. This implies that stroke patients had low level of satisfaction with community reintegration in Kano metropolis. This finding may be attributed to the significant number of those that lost their employment, the significant reduction in earnings and the loss of ability to return to driving post-stroke. Another possible reason for the poor level of community reintegration in this study could be stroke-related weakness, since more than half of the participants required some level of physical assistance with activities of daily living.

The outcome of this study was however different from those of Obembe et al $(2010 ; 2013)$ who reported moderate levels of community reintegration for most of their study participants. The finding of this study was also different from that of Carter et al (2000), who reported that fifty-five percent of their study participants were fully satisfied with community reintegration. One possible reason for the differing outcome between this study and that of Obembe et al $(2010 ; 2013)$ and Carter et al (2000) could be the difference in the functional status of participants with most participants in the latter 3 studies having slight disability. Furthermore, the mean stroke duration in Obembe et al,
(2010) was about 19 months and it is possible that most of the participants in their study could have had enough time to readjust both socially and psychologically to resume living in the community, unlike most of the participants in this study whose duration of stroke were between three and six months.

The significant relationship observed between community reintegration and physical function is consistent with the findings of many studies (Beckley, 2007; Baseman et al 2010; Akosile et al, 2012; Obembe et al, 2013; Hamzat et al, 2014). The goal for many stroke survivors is to achieve a level of physical function that will enable them to return to their homes (Kwakkel et al, 2004) and to ultimately reintegrate into the larger community. The implication of the finding of this study is that increased level of physical function will promote better satisfaction with community reintegration.

Additionally, the significant relationship that existed between social support and community reintegration in this study is consistent with the outcomes of many studies. Glass and Maddox (1992), Glass et al. (1993), and Tsouna-Hadjis et al (2005) have all reported that higher levels of social support were associated with enhanced social involvement leading to better community reintegration. This implies that adequate support from members of the family, friends and 
significant others will lead to more satisfaction with community reintegration

Moreover, it was observed that a significant number of stroke survivors in this study could not return to work poststroke. Work helps one to engage in social interactions, earn some money and have self-confidence. The inability of most of the stroke survivors in this study to return to work could stem from their low score on physical function. Previous studies have reported low levels of community reintegration for individuals who could not return to gainful employment post-stroke (Baseman et al 2010, Akosile et al, 2012). Therefore, return to gainful employment post-stroke is a great step towards ensuring satisfaction with community reintegration. Finally, a significant number of stroke survivors in this study could not return to driving poststroke. This finding may not be unconnected with the large number of participants who had severe restrictions to their community reintegration. This outcome corroborates that of Finestone et al (2010), who found that non-drivers poststroke had a lower reintegration score than drivers. Affected persons found it difficult going to work, shopping, recreation, and attending social gatherings.

The main limitation observed in this study was that FIM, which is meant to assess functional status of patients who are on hospital admission through direct observation of task performance, was used in this study on patients coming for outpatient treatment. Consequently, some basic functions such as bathing, using the toilet and sphincter control could not be assessed directly and the patients had to be asked instead.

\section{CONCLUSION}

The level of community reintegration of most stroke survivors in Kano metropolis is not satisfactory. The majority suffered significant loss of employment and earnings and inability to drive post-stroke. Increased levels of social support and adequate recovery of physical functions are likely to improve their community reintegration. Successful community reintegration of stroke survivors requires that multiple factors be put into consideration when planning holistic rehabilitation with inputs from different rehabilitation experts.

\section{Conflict of Interest}

The authors declare that there is no any conflict of interest

\section{References}

Akhtar A., Rahman A., Husain M., Chaudhry I.B., Duddu V. and Husain N. 2010. Multidimensional scale of perceived social support: Psychometric properties in a South Asian population. The Journal of Obstetrics and Gynaecology Research 36(4): 845-51.

Akosile C.O., Adegoke B.O.A. and Fabunmi A.A. 2012. Community reintegration and related factors in a Nigerian stroke sample. Proceedingss of 9th WCPT Africa Region Congress Kenya.

http://www.wcptafrica.org/conferences/index.php/conf/keny a2012/paper/view/112.

Baseman S.I., Fisher K., Ward L. and Bhattacharya A. 2010. The relationship of physical function to social integration after stroke. The Journal of Neuroscience Nursing 42(5): 237-44.

Beckley M.N. 2007. The influence of the quality and quantity of social support in the promotion of community participation following stroke. Australian Occupational Therapy Journal 54(3): 215-220

Bian C., Li C., Duan Q. and Wu H. 2011. Reliability and validity of patient health questionnaire: Depressive syndrome module for outpatients. Scientific Research and Essays 6(2): 278-282. http://www.academicjournals.org/SRE

Brosseau L. and Wolfson C. 1994. The inter-rater reliability and construct validity of the functional independence measure for multiple sclerosis subjects. Clinical Rehabilitation 8(2): 107115. doi: $10.1177 / 026921559400800203$

Carter B.S., Buckley D., Ferraro R., Rordorf G., Ogilvy C.S. 2000. Factors associated with reintegration to normal living after subarachnoid hemorrhage. Neurosurgery 46: 1326-34.

Chau J.P.C., Thompson D.R., Twinn S., Chang A.M. and Woo J. 2009. Determinants of participation restriction among community dwelling stroke survivors: A path analysis. $B M C$ Neurology 9: 49.

Dijkers M. 1998. Community integration: Conceptual issues and measurement approaches in rehabilitation research. Topics in Spinal Cord Injury Rehabilitation 4: 1-17.

Finestone H.M., Guo M., O'Hara P., Greene-Finestone L., Marshall S.C., Hunt L., Biggs J., Jessup A. 2010. Driving and reintegration into the community in patients after stroke. The Journal of Injury Function and Rehabilitation 2(6): 497503.

Glass T.A., Maddox G.L. 1992. The quality and quantity of social support: Stroke recovery as psycho-social transition. Social Science and Medicine 34: 1249-1261.

Glass T.A., Matchar D.B., Belyea M., Feussner J.R. 1993. Impact of social support on outcome in first stroke. Stroke 24: 64-70.

Hammash M.H., Hall L.A., Lennie T.A., Heo S., Chung M.L., Lee K.S. and Moser D.K. 2013. Psychometrics of the PHQ-9 as a measure of depressive symptoms in patients with heart failure. European Journal of Cardiovascular Nursing 12(15): 446-453.

Hamzat T.K., Olaleye O.A. and Akinwumi O.B. 2014. Functional ability, community reintegration and participation restriction among community dwelling female stroke survivors in Ibadan. Ethiopian Journal of Health Sciences 24(1).

Hannan J. Alce M. and Astros A. 2016. Psychometric properties of the newly translated creole multidimensional scale of perceived 
social support and perceived adequacy of resource scale and the relationship between perceived social support and resources in Haitian mothers in the US. BMC Psychology 4: 7.

Hitzig S.L., Romero Escobar E.M., Noreau L. and Craven B.C. 2012. Validation of the Reintegration to Normal Living Index for community-dwelling persons with chronic spinal cord injury. Archive of Physical Medicine and Rehabilitation 93(1): 108-14.

Hsueh I.P., Lin J.H., Jeng J.S., Hsieh C.L. 2002. Comparison of the psychometric characteristics of the functional independence measure, 5 item Barthel index, and 10 item Barthel index in patients with stroke. Journal of Neurology Neurosurgery and Psychiatry 73(2): 188-90.

Konzen B. and Shin K. 2006. Physical medicine and rehabilitation. In: Bruera E., Higginson J.I., Ripamonti C. and Von Gunten C. (eds). Textbook of Palliative Medicine. London: Hodder Arnold, pp. 892.

Kroenke K., Spitzer R., Williams J.B.W. 2001. The PHQ-9: Validity of a brief depression severity measure. Journal of General, Internal Medicine 16: 606-613.

Kwakkel G., Kollen B., Lindeman E. 2004. Understanding the pattern of functional recovery after stroke: Facts and theories. Restorative Neurology and Neuroscience 22: 281-99.

Linacre J.M. 2000. FIM levels as ordinal categories. Journal of Outcome Measurements 4(2): 615-633.

Mayo N.E., Wood-Dauphinee S., Coté R., Gayton D., Carlton J., Buttery J., Tamblyn R. 2000. There's no place like home. An evaluation of early supported discharge for stroke. Stroke 31: 1016-1023.

Meta Data Online Registry. 2012. Functional Independence Measure. Accessed at http://meteor.aihw.gov.au/content/index.phtml/itemId/495857

Mothabeng D.J., Eksteen C.A., Westaway M. 2012. Psychometric validation of the Reintegration to Normal Living Index in people living with spinal cord injuries. South African Journal of Physiotherapy 68(2).

Murtezani A., Hundozi H., Gashi S., Osmani T., Krasniqi V., Rama B. 2009. Factors associated with reintegration to normal living after stroke. Medicinski Archiv 63(4): 216-9.
Obembe A.O., Johnson O.E., Fasuyi T.F. 2010. Community reintegration among stroke survivors in Osun, Southwestern Nigeria. African Journal of Neurological Sciences 29(1).

Obembe A., Mapayi B., Johnson O., Agunbiade T., Emechete A. 2013. Community reintegration in stroke survivors: Relationship with motor function and depression. Hong Kong Physiotherapy Journal 31: 69e74.

Pang M.Y.C., Eng J.J., Miller W.C. 2007. Determinants of satisfaction with community reintegration in older adults with chronic stroke: Role of balance self-efficacy. Physical Therapy 87: 282-291.

Rizwan M. and Aftab S. 2009. Psychometric properties of the multidimensional scale of perceived social support in Pakistani young adults. Pakistan Journal of Psychology 40(1): 51-65.

Salter K., Allen L., Richardson M., Teasell R. and Foley N. 2013. Community Reintegration. www.ebrsr.com

Sprint G., Cook D.J., Weeks D.L., Borisov V. 2015. Predicting functional independence measure scores during rehabilitation with wearable inertial sensors. IEEE Access 3: 1350-1366.

Stewart R.C., Umar E., Tomenson B. and Creed F. 2014. Validation of the Multi-dimensional Scale of Perceived Social Support and the relationship between social support, intimate partner violence and antenatal depression in Malawi. BMC Psychiatry 14: 180. http://www.biomedcentral.com/1471244X/14/180.

Tsouna-Hadjis E., Vemmos K.N., Zakopoulos N. and Stamatelopoulos S. 2000. First-stroke recovery process: The role of family social support. Archive of Physical Medicine and Rehabilitation 81: 881-887.

Wongpakaran T., Wongpakaran N. and Ruktrakul R. 2011. Reliability and validity of the Multidimensional Scale of Perceived Social Support (MSPSS): Thai version. Clinical Practice \& Epidemiology in Mental Health 7: 161-166.

Wood-Dauphinee S.L., Opzoomer A., Williams J.I. et al. 1988. Assessment of global function: The Reintegration to Normal Living Index. Archive of Physical Medicine and Rehabilitation 69: 583-590. 